Research Article

\title{
Study on Calculation of Bearing Capacity of Axially Loaded CFRP-Strengthened Cold-Formed Thin-Walled Lipped Channel Steel Columns
}

\author{
Yanan Sun (D), ${ }^{1}$ Pengfei $\mathrm{Li}^{2}$ and Guojin Qin (iD) ${ }^{3}$ \\ ${ }^{1}$ School of Civil Engineering, Qingdao University of Technology, Qingdao, Shandong 266033, China \\ ${ }^{2}$ College of Civil Engineering, Zibo Architectural Design and Research Institute, Zibo, Shandong 255000, China \\ ${ }^{3}$ School of Mechatronic Engineering, Southwest Petroleum University, Chengdu, Sichuan 610500, China \\ Correspondence should be addressed to Guojin Qin; qgj_swpu@sina.com
}

Received 13 October 2019; Revised 14 March 2020; Accepted 30 September 2020; Published 19 October 2020

Academic Editor: Arnaud Perrot

Copyright (c) 2020 Yanan Sun et al. This is an open access article distributed under the Creative Commons Attribution License, which permits unrestricted use, distribution, and reproduction in any medium, provided the original work is properly cited.

With the development of carbon fiber reinforced composites and the continuous improvement of the properties of bonding agents, scholars recommended using carbon fiber reinforced plastics (CFRP) to enhance cold-formed thin-walled C-shaped steel structures. It can provide a fast and effective way to strengthen and repair damaged steel structures. However, discussion on the bearing capacity calculation of cold-formed thin-walled C-section steel column strengthened by CFRP was limited. Also, the relevant influencing factors (the number of CFRP reinforcement layers), the orientation of CFRP (horizontal, vertical), and the location of CFRP reinforcement (web + flanges + lips, web + flanges, web, and flanges) were overlooked in calculating the bearing capacity of cold-formed thin-walled C-section steel column strengthened by CFRP. Then, the calculation result of the load capacity will be inaccurate. This work, therefore, studied the effects of CFRP reinforcement layers, CFRP direction, and CFRP reinforcement position on the ultimate load of CFRP-strengthened cold-formed thin-walled C-section steel column. A threedimensional (3D) finite element model of cold-formed thin-walled steel strengthened by CFRP was established to discuss the bearing capacity under axial compression. Furthermore, a method for calculating the bearing capacity of the CFRP-strengthened cold-formed thin-walled C-section steel column was proposed based on the direct strength methods (DSM). The results indicate that not only the slenderness ratio, section size, and length of members but also the number of CFRP reinforcement layers and orientation of CFRP have an impact on the calculation of bearing capacity. The equation modified in this work has excellent accuracy and adaptability. Predicting the bearing capacity of reinforced members is necessary to give full play to the performance of CFRP accurately. Thus, the methods proposed can provide a reference value for practical engineering.

\section{Introduction}

Currently, lightweight steel structures with cold-formed thin-walled steel frames become increasingly widely used in the field of structural engineering. Cold-formed thin-walled steel, wood, bamboo, and other materials can be combined into truss beams, columns, and other major bearing components. Also, it can be used for roof panels, floor slabs, and other minor components. Cold-formed thin-walled steel is a type of high-efficiency section steel, in which a thin steel plate is bent into various section shapes by rolling or stamping at room temperature. It can bear larger loads with less material by changing the section shape rather than increasing the section area [1]. While cold-formed thinwalled steel has been used efficiently, due to the improvement in the yield strength of the materials used, ultrathin plate and increasingly complex cross-section forms have led to problems with component stability. Generally, local buckling, distorted buckling, and overall buckling will occur on cold-formed open-section members. The interaction between two or three of buckling modes can also occur under certain conditions. In local buckling, the plate rotates around the intersection line of the plate, but the intersection line remains straight. In overall buckling, the whole cross- 
section rotates or moves laterally, but the cross-section shape does not change. In distorted buckling, the plate revolves around the intersection line of the plate, and some of the intersection lines of the plate no longer maintain straight lines. The cross-section shape and contour size also change. Under these circumstances, external strengthening using CFRP has been identified as a potential option to enhance the strength of existing columns, as this can provide a high strength-to-weight ratio and stiffness $[2,3]$. Furthermore, the durability and corrosion-resistant characteristics of CFRP will enhance the long-term structural performance of steel columns. The relevant research shows that the use of CFRP to strengthen the stability of steel structures is effective [4], and the use of CFRP to reinforce cold-formed steel lipped channel columns is also increasingly common.

Previous studies focused on the repair of naturally corroded I-girders. Girders were artificially notched in the lab to simulate damage, fatigue-damaged members. Also, the durability of the bond between steel and FRP materials can be used to investigate the occurrence of galvanic corrosion associated with combining steel and carbon fiber. Narmashiri et al. [5] conducted static load tests on 13 CFRPstrengthened beams and compared different reinforcement forms. It can be concluded that there were four failure modes in CFRP-strengthened beams, that is, transverse cracking of the carbon plate, interfacial peeling at the loading position, interlaminar failure of the carbon plate at the end, and interfacial peeling at the end. Yuan et al. [6] applied the basic theory of fracture mechanics to propose cohesive contact, cohesive element, and extended finite element computational models to simulate an experimental H-beam. The failure parameters of the model were determined by comparing the model results with the tests, and the cohesive contact model was used for numerical modeling and parameter analysis, and the cohesive contact model was used for numerical modeling and parameter analysis. Bambach et al. [7] investigated the effect of CFRP strengthening in short square hollow section (SHS) columns constructed of slender cross sections. They achieved up to twice the axial compression capacity by a combination of transverse and longitudinal layers. Both transverse and longitudinal CFRP layers were used to reduce the membrane strains that develop in both directions with local buckling in the column. It can be found that slender section columns undergo larger buckling deformations, and, consequently, a greater increase in capacity can be achieved using CFRP. Imran et al. [8] developed a numerical simulation in ABAQUS in which CFRP and an adhesive were modeled using continuum and cohesive elements by employing Hashin and cohesive law criteria. Thereby a new set of design equations based on the direct strength method (DSM) was proposed to determine the axial compression capacity of CFRP-strengthened SHS columns subject to local buckling. Fernando et al. [9] performed an experimental study aimed at clarifying the effects of adhesive properties on the failure mode and load-carrying capacity. Four different failure modes were observed in these tests, including adhesion failure, cohesion failure, combined adhesion and cohesion failure, and interlaminar failure of the CFRP plates. The tests also revealed that an adhesive with greater ultimate tensile strain leads to the higher load-carrying capacity of the strengthened rectangular hollow section (RHS) tube. Al-Saidy [10] focused on the behavior of steel composite beams that were intentionally damaged at their tension flange to simulate corrosion and then repaired with CFRP plates attached to the tension area side. A nonlinear analytical procedure was also developed to predict the behavior of the section/member in the elastic, inelastic, and ultimate states to facilitate the implementation of this strengthening technique. The test results showed a significant increase in the strength and stiffness of the repaired beams. Thus, the research on CFRP strengthening of steel structures has gradually matured. It also focused on three aspects, including enhancing axially compressed members (e.g., SHS, T, H, circular steel tube, and composite steel members) to improve the bearing capacity after strengthening, reinforcing damaged steel beams and nondestructive steel beams, and improving the fatigue resistance of steel members.

The use of fiber-reinforced polymer (FRP) sheets and strips has been successfully demonstrated in retrofits of concrete structures. However, studies on using FRP for the retrofitting of steel structures were scarce. Most experiments and numerical simulations in the literature involved flexural members [4, 10-15]. Only a few considered compressive members [3, 16, 17]. Furthermore, research on particular section forms strengthened by CFRP, such as cold-formed thin-walled C-section steel, has rarely been performed. Also, there were few studies on calculating the bearing capacity of cold-formed thin-walled C-section steel strengthened with CFRP. The calculation accuracy of the proposed formulas was poor. Scholars compared the ultimate load of CFRPstrengthened cold-formed thin-walled steel under axial compression obtained with experimental, numerical, and direct strength methods. Results showed that the average values of the three ways were very similar. Nevertheless, the analysis revealed that the results of DSM were occasionally conservative, and the maximum error of the three methods was approximately $20 \%$, which will lead to a failure to utilize the full performance of the material. These experimental studies $[3,7,16]$ have led to the development of design equations for predicting the axial compression capacity of CFRP-strengthened short steel tubular columns. Bambach et al. [7] developed a design approach in which the theoretical, critical elastic buckling stress of a CFRP-strengthened short SHS column was used to determine its axial compression capacity. The assumption of the model proposed was that the effects of both the transverse and longitudinal CFRP layers were the same in restricting the local buckling failure, contrary to the existing results that the effect of CFRP strengthening depended on the orientation of the CFRP layers $[16,18]$.

Therefore, this work aimed to improve upon the works of Kalavagunta et al. [19], thereby proposing a new set of design equations based on the DSM to predict the axial compression capacity of CFRP-strengthened cold-formed thinwalled C-section steel columns. Cold-formed thin-walled C-section steel is seldom used for axially compressed members. Thus, it is particularly important to investigate the 
changes in mechanical properties, the stability of the members, and the calculation formula for bearing capacity for this type of member under axially compressed conditions after the attachment of CFRP. Specifically, a 3D FE model was developed to verify the correctness of the numerical simulation and predict the ultimate bearing capacity of coldformed thin-walled C-section steel strengthened with CFRP based on the AISI-DSM. The number of CFRP reinforcement layers, CFRP orientation (horizontal, vertical, and oblique $45^{\circ}$ ), and CFRP reinforcement location (web + flanges + lips, web + flanges, web-only, and flanges only) were investigated in terms of previous research variables. Load-displacement curves were obtained, and the impact on the ultimate bearing capacity of the components was also analyzed. Besides, the calculation formulas for bearing capacity proposed in previous studies were modified and improved. The influence of the number of CFRP reinforcement layers and orientation of the CFRP were taken into account in the improved formulas to obtain more accurate bearing capacity results. Computed results and numerical simulation were compared in Section 4 to examine the validity and reliability of the proposed method. Overall, the investigation aims to provide engineers with a basic understanding of the performance of CFRP-reinforced cold-formed thin-walled steel. With better estimates of the utilization rate of materials, while ensuring the strength of structural components, the material can be saved, which can provide a reference for future engineering construction projects.

\section{Numerical Modelling}

A numerical investigation is performed using the ABAQUS CAE finite element (FE) software to simulate axial compression tests and the bearing capacity of CFRP-strengthened cold-formed steel lipped channel columns. Many factors, such as the element type, material properties, grid generation, boundary conditions, and solver setting, are considered in this work, to build an appropriate numerical model.

2.1. Initial Conditions. The FE model is divided into three parts, including the cold-formed steel lipped channel columns, adhesive, and CFRP. Figure 1 shows the CFRPstrengthened cold-formed thin-walled short columns built by ABAQUS/CAE with a thickness of $0.1 \mathrm{~mm}$. From the literature $[20,21]$, the typical thickness of the adhesive is $0.1-0.3 \mathrm{~mm}$. The adhesive is established in the cold-formed lipped channel steel and the first layer of CFRP during the modeling process. As interlayer debonding does not occur in CFRP-CFRP [8], bond failure can only be simulated between the cold-formed thin-walled lipped channel steel and the CFRP.

The selection of appropriate element types plays an essential role in ensuring the accuracy of the simulation results. The cold-formed steel lipped channel columns are simulated using 4-node S4R shell elements with reduced integration and hourglass control. An 8-node 3D cohesive element (COH3D8) is used to model the adhesion layer to predict adhesive behavior and failure [20, 22-24]. The carbon fiber sheet is developed by 8-node quadrilateral inplane general-purpose continuum shell elements (SC8R) with reduced integration and hourglass control. Continuous shell elements can accurately predict the failure of composite materials and are thus more suitable for CFRP modeling [20, 22-26]. Material orientations are assigned to each CFRP layer by creating two different sections for longitudinal and transverse layers. Besides, the element deletion option is enabled for both cohesive and continuum elements with a maximum degradation of $95 \%$. A mesh density of $10 \mathrm{~mm}$ is adopted for the short column, while a mesh density of $30 \mathrm{~mm}$ is used for the long column, and the interacting surfaces are connected by sharing the nodes of the base surface in the FE model.

\subsection{Mechanical Properties of Materials}

2.2.1. Cold-Formed Steel. The cold-formed steel lipped channel columns are built as an elastic-plastic material with strain hardening. The experimentally measured stress-strain curve along with a yield strength and elastic modulus of $550 \mathrm{MPa}$ and $205 \mathrm{GPa}$, respectively, is used to develop the FE model [19]. The stress-strain curve of cold-formed steel is shown in Figure 2.

2.2.2. Adhesive. MC-Dur 1280 epoxy resin (adhesive for CFRP strips and flat-bar steel for structural strengthening) is used to bond the carbon fabric to the cold-formed channel columns. The adhesive layer between the steel and the first CFRP layer is established by a coupled cohesive zone model based on traction separation law. The traction separation law considers traction and separation in three directions, including the normal direction and two shear directions. The normal direction and shear directions are denoted by $t_{n}, t_{s}$, and $t_{t}$, respectively, while the corresponding separations are represented by $\delta_{n}$, $\delta_{s}$, and $\delta_{t}$, respectively. Consequently, the interface behavior of the adhesive from the initial reaction to failure can be expressed as follows:

$$
\left[\begin{array}{c}
t_{n} \\
t_{s} \\
t_{t}
\end{array}\right]=\left[\begin{array}{ccc}
k_{n n} & 0 & 0 \\
0 & k_{s s} & 0 \\
0 & 0 & k_{t t}
\end{array}\right]\left[\begin{array}{l}
\delta_{n} \\
\delta_{s} \\
\delta_{t}
\end{array}\right],
$$

where $k_{n n}, k_{s s}$, and $k_{t t}$ are the elastic stiffness in the normal and shear directions, respectively:

$$
k_{n n}=\frac{E_{a}}{T_{0}},
$$

where $E_{a}$ is the elastic modulus and $T_{0}$ is the thickness of the adhesive [22]:

$$
k_{s s}=k_{t t}=3\left(\frac{G_{a}}{T_{0}}\right)^{0.65},
$$

where $G_{a}$ is the shear modulus of the adhesive. The stiffness of the adhesive should be large enough to provide reasonable 

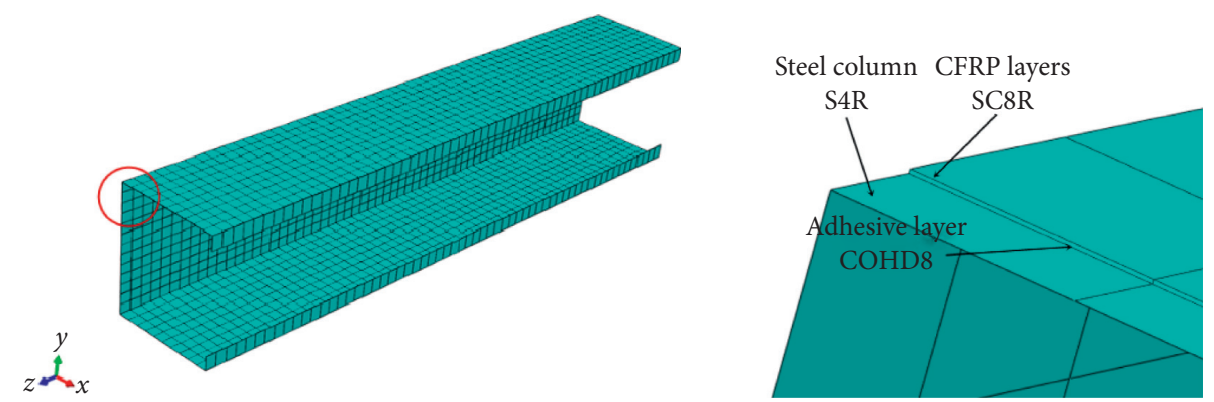

FIGURE 1: FE model of CFRP-strengthened cold-formed thin-walled C-section steel column.

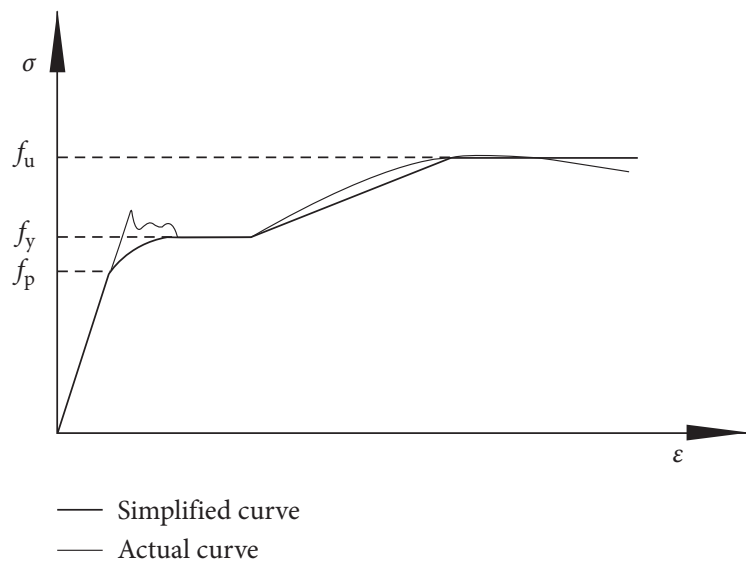

FIgURE 2: Stress-strain curve of cold formed steel.

stiffness but not large enough to cause interface vibration [27]. $k_{s s}$ and $k_{t t}$ are determined by comparing the experimental results [28] (Table 1).

The failure criterion used for damage is QUADS, expressed in (4). Damage initiation occurs when the damage function reaches a value of 1 based on this criterion:

$$
\left\{\frac{\left\langle t_{n}\right\rangle}{\sigma_{\max }}\right\}+\left\{\frac{t_{s}}{\tau_{\max }}\right\}+\left\{\frac{t_{t}}{\tau_{\max }}\right\}=1,
$$

where $\sigma_{\max }$ is the tensile strength and $\tau_{\max }$ is shear strength, which is determined from the following [22]:

$$
\tau_{\max }=0.9 \sigma_{\max } .
$$

An energy-based linear softening approach is applied in ABAQUS. Benzeggagh-Kenane (BK) fracture energy-based mixed-mode law is used in this work [29]:

$$
G_{\mathrm{I}}+\left(G_{\mathrm{II}}-G_{\mathrm{I}}\right)\left(\frac{G_{S}}{G_{t}}\right)^{\eta}=G_{n},
$$

where $G_{n}, G_{s}$, and $G_{t}$ represent the normal and shear directions, respectively. $G_{I}$ and $G_{I I}$ are the corresponding maximum fracture energies, which cause failures in the normal and shear directions, respectively.

The values of $G_{\mathrm{I}}$ and $G_{\mathrm{II}}$ are obtained from the literature [20]. The value of $\eta$ is 1.55 [29]. Not all parameters used in the FE method are mentioned in [19]. The above data obtained from the material properties test is selected for the FE simulations, which is in agreement with the experimental data in [19]. The material properties of the adhesive layer are summarized in Table 1.

2.2.3. CFRP. The CFRP composite is developed by a laminar-type elastic material. The damage of the composite is simulated using the Hashin failure criteria [30,31]. Owing to CFRP exhibits no visible plastic deformation in the initial stage of damage. The Hashin damage model can predict the destruction of these materials successfully. The damage evolution begins once the damage criterion for a given failure mode is satisfied. The energy dissipation is equal to the critical fracture energy for a given failure mode. In the FE model, it is necessary to provide the fracture energy for the failure modes. The tensile strength of CFRP is $4830 \mathrm{MPa}$ with a tensile modulus of $230 \mathrm{GPa}$, a weight of $300 \mathrm{~g} / \mathrm{m}^{2}$, an ultimate elongation of $2 \%$, and fiber thickness of $0.166 \mathrm{~mm}$. The compressive strength of commonly used CFRP varies from $9 \%$ to $60 \%$ of the tensile strength $[26,32]$. Hence, the longitudinal compressive strength of the CFRP is assumed to be $20 \%$ of the tensile strength [8]. The transverse tensilecompressive and longitudinal-transverse shear strengths are supposed to be $10 \%$ of the tensile strength [25,33]. Poisson's ratio of the CFRP is 0.33 [34]. Finally, a viscosity coefficient of 0.0001 is used in the FE model [26]. The related material parameters of CFRP can be obtained from the material properties experiments, as summarized in Table 2. All the material properties are obtained from the technical data provided by the manufacturer.

2.3. Boundary Conditions and Analysis Procedure. A hinge loads the thin-walled steel at both ends. UX, UY, and URZ are restrained at the loading end, while UX, UY, UZ, and URZ are restrained at the nonloading end. Loading is performed in the Z-direction. It is transformed into concentrated force loading. The axial compression load is incrementally applied to the top reference point. All the translational and rotational degrees of freedom are fixed at the top and bottom reference points (Figure 3). An independent reference node is created at the center of the crosssection at each end of the column. All the peripheral nodes of the column are constrained to these reference nodes via beam-type multiple point constraints (MPC). The reference point is defined at the shear center of the cold-formed thinwalled steel. The shear center position is determined as specified in Chinese Standard (GB50018-2002)- 
Table 1: Properties of adhesive.

\begin{tabular}{lc}
\hline Parameter & Value \\
\hline$E_{a}$ & $8.6 \mathrm{GPa}$ \\
$k_{n n}$ & $86000 \mathrm{MPa}$ \\
$k_{s s}=k_{t t}$ & $1.0 \times 10^{13} \mathrm{~N} / \mathrm{m}^{3}$ \\
$G_{\mathrm{I}}$ & $3900 \mathrm{~N} / \mathrm{m}$ \\
$G_{\mathrm{II}}$ & $11000 \mathrm{~N} / \mathrm{m}$ \\
$\sigma_{\max }$ & $20 \mathrm{MPa}$ \\
$T_{\max }$ & $18 \mathrm{MPa}$ \\
\hline
\end{tabular}

TABle 2: Properties of CFRP.

\begin{tabular}{lc}
\hline Parameter & Value \\
\hline$E_{1}$ & $230 \mathrm{GPa}$ \\
$E_{2}$ & $10 \mathrm{GPa}$ \\
$\mathrm{Nu}_{12}$ & 0.3 \\
$G$ & $5 \mathrm{GPa}$ \\
$T_{L}$ & $4.83 \mathrm{GPa}$ \\
\hline
\end{tabular}

approximate formula B.2.6 for inward edging channel steel [35]. The following equation is used to calculate the position of the shear center. The section diagram is shown in Figure 4:

$$
Z_{0}=\frac{b(b+2 a)}{h+2 b+2 a}
$$

where $Z_{0}$ is the position of the shear center.

We couple the reference nodes with cold-formed thinwalled steel sections. The adhesive layer is established between the cold-formed thin-walled steel and the first CFRP layer. Tie constraints are applied between the adhesive layer and the cold-formed thin-walled steel and between the adhesive layer and the CFRP.

Firstly, an elastic buckling analysis is conducted to determine the buckling load and buckling mode of the column. Next, the risk method is used to perform a nonlinear analysis to assess the load-displacement characteristics and the failure load of the column.

For cold-formed thin-walled channel steel, the initial defects include residual stress and geometric defects. To date, there have been few studies on the initial residual stress of cold-formed thin-walled channel steel. Thus, the influence of residual stress is neglected in this paper. For initial geometric imperfections, the overall initial bending and torsion deformation amplitude is $\mathrm{L} / 1000$ according to the technical code of cold-formed thin-walled steel structures (China Standard (GB50018-2002)) [35]. An eigenvalue buckling analysis is conducted to obtain the first-order buckling mode. Then the buckling mode is multiplied by $\mathrm{L} / 1000$ to get the overall geometric defect of the specimen.

\section{Results and Discussion}

The results of CFRP-strengthened cold-formed steel-lipped channel section simulations are always affected by various factors. The ultimate bearing capacity calculated for three types of component sizes and CFRP reinforcement positions in cold-formed thin-walled steel (plain, full, and web) is first compared to experimental data from [19]. The FE models are also validated using the experimental results in [19]. Also, a parametric study is then conducted to investigate the effects of parameters such as the number of CFRP reinforcement layers, the orientation of the CFRP, and location of CFRP reinforcements.

\subsection{Comparison of Experimental Data and Numerical} Simulation. A total of three components (C7510, C7512, and C10010) are simulated based on the details listed in Table 3. The section sizes of the three series of members are shown in Figure 5. A cold-formed steel-lipped channel section with a yield stress of $550 \mathrm{MPa}$ and modulus of elasticity of $205 \mathrm{GPa}$ is used for all steel sections. The crosssectional dimensions of specimens C7510, C7512, and C10010 with lengths of $500 \mathrm{~mm}, 600 \mathrm{~mm}$, and $700 \mathrm{~mm}$, respectively, are considered in the modeling. The basic dimensions and properties of the three different components are summarized in Table 3.

Figure 6 shows the experimental model of cold-formed thin-walled steel bonded with CFRP from [19]. Also, it gives that the surface of the steel needs to be cleaned to remove dust and other contaminants. The carbon fiber sheets are fabricated following the standard size. The epoxy adhesive is smeared uniformly on the surface of the components and the CFRP sheets. The side of the component to adhere to the CFRP is exposed to the top and gradually pressed along the direction of the fiber. Three types of specimens are prepared for testing, including plain cold-formed steel-lipped channel sections, a cold-formed steel section with a CFRPstrengthened web only and, next, a cold-formed steel section with full CFRP strengthening (Figure 6). Note that the basic bond strength of the epoxy resin should reach at least $15 \mathrm{~d}$ when CFRP is used to reinforce cold-formed thin-walled steel members.

Three CFRP reinforcement types are adopted for the members in Table 1 for the numerical simulation to verify the FE model, which is the same as those used in the experiments: unreinforced reinforced webs and adequately reinforced. A comparison between the numerical simulation results and the experimental data is shown in Figure 7.

From Figure 7, the comparison between the experimental data in reference and the simulated results obtained with the FE model exhibit a slight error of approximately $5 \%$. The reason is that it is difficult to control the axial loading in the experiment. Also, the shear center of the cold-formed thin-walled steel is hard to determine accurately. Thus, a slight difference in the introduction of the defect coefficient may also result in the error in the final data. In general, the numerical simulation results are in good agreement with the experimental data from [19]. In this work, the cooperative deformation of the steel plate and CFRP is mainly considered, but the failure mode between CFRP and steel interfaces is not found. Consequently, it can be considered that the bond performance of adhesive is excellent. Besides, there is no separation between CFRP and steel members in the process of ultimate load research. Therefore, it can be concluded that the ultimate compressive strength increases between $6 \%$ and $12 \%$ after strengthening the webs with 


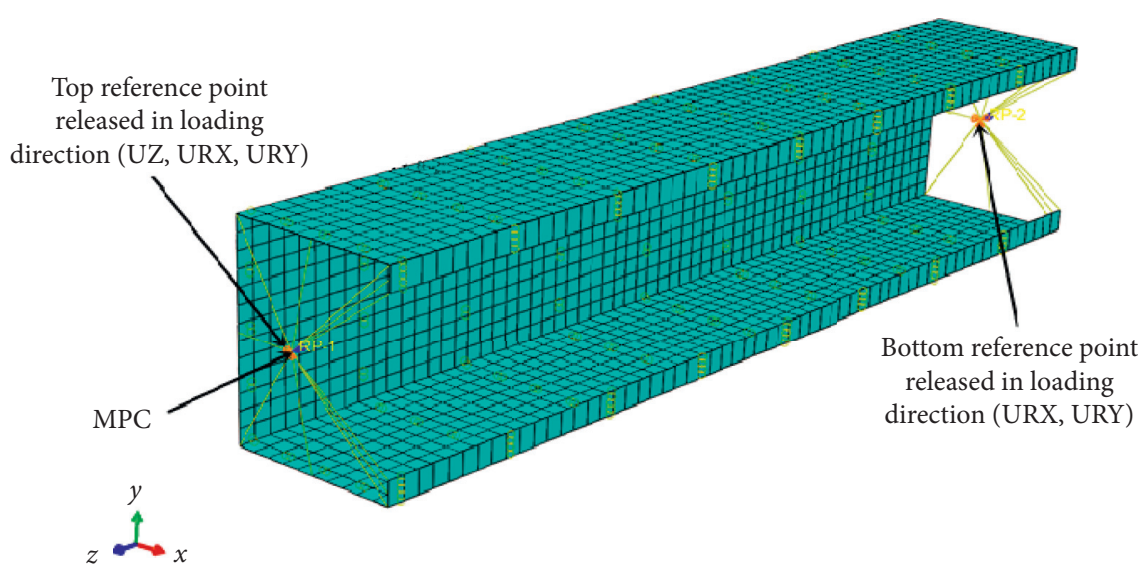

FIgURE 3: Boundary conditions.

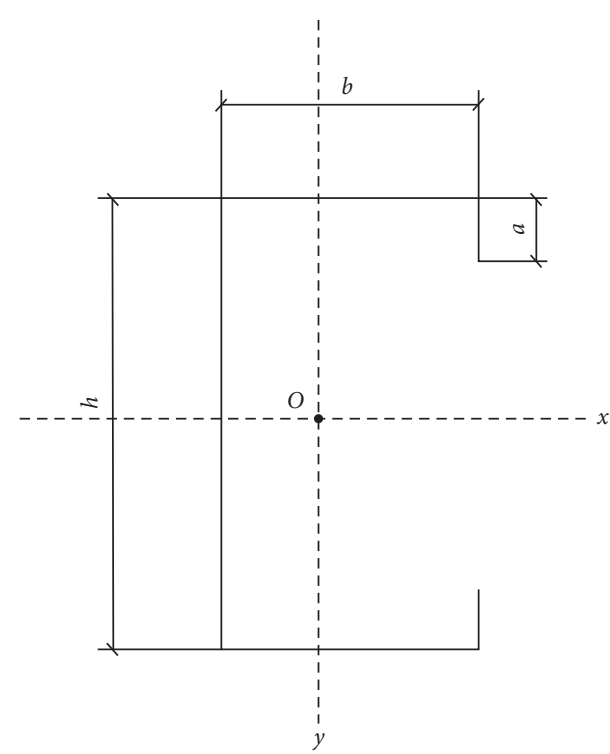

Figure 4: Section diagram.

TABle 3: Dimensions and properties [19].

\begin{tabular}{lccc}
\hline Properties & C7510 & C7512 & C10010 \\
\hline Thickness $(\mathrm{mm})$ & 1 & 1.2 & 1 \\
Web $(\mathrm{mm})$ & 75 & 75 & 100 \\
Flange $(\mathrm{mm})$ & 33 & 33 & 46 \\
Lip $(\mathrm{mm})$ & 7 & 7 & 12 \\
Yield stress $(\mathrm{MPa})$ & 550 & 550 & 550 \\
Area $\left(\mathrm{mm}^{2}\right)$ & 137 & 204 & 216 \\
$I x x \times 10^{4}\left(\mathrm{~mm}^{4}\right)$ & 12.2 & 18.9 & 36.4 \\
$I y y \times 10^{4}\left(\mathrm{~mm}^{4}\right)$ & 2.85 & 5.2 & 7.55 \\
Section modulus $Z x \times 10^{3}\left(\mathrm{~mm}^{3}\right)$ & 3.25 & 5.14 & 7.13 \\
Section modulus $Z y \times 10^{3}\left(\mathrm{~mm}^{3}\right)$ & 1.02 & 1.84 & 2.19 \\
Radius of gyration, $R x(\mathrm{~mm})$ & 29.84 & 30.43 & 41.1 \\
Radius of gyration, $R y(\mathrm{~mm})$ & 12.67 & 15.96 & 18.7 \\
\hline
\end{tabular}

CFRP. The average increase is $10 \%$. After strengthening the webs with CFRP, the ultimate compressive strength increases by $11 \%$ to $18 \%$. From all cases, the ultimate bearing capacity of the member will increase its stiffness and
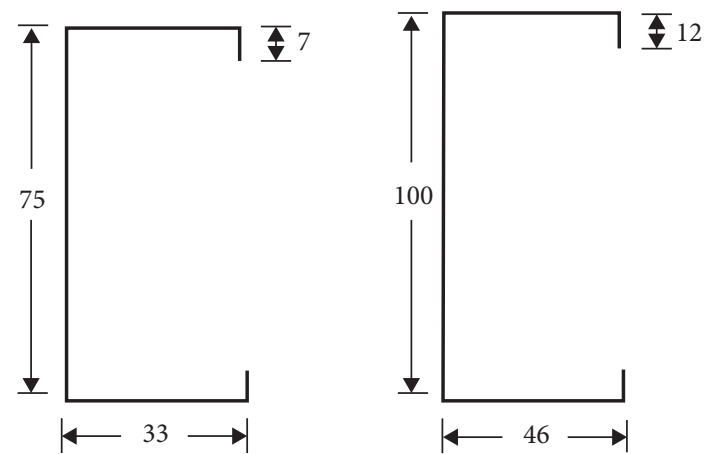

Figure 5: Typical cross section of C7510, C7512, and C10010 (mm).

resistance to varying degrees depending on the location of the CFRP reinforcement.

3.2. Numerical Model Parameter Analysis. In the modeling, the component size parameters are selected as follows: $b_{w}=125 \mathrm{~mm}, b_{f}=102 \mathrm{~mm}, b_{l}=14 \mathrm{~mm}, t=1 \mathrm{~mm}$ (short column), and $t=1.5 \mathrm{~mm}$ (long column). The column CFRP strengthening can always increase the critical buckling load, but it does not affect the length range corresponding to local, distorted, and global buckling [34]. Accordingly, the component lengths are chosen as $L=600 \mathrm{~mm}$ (short column) and $L=2200 \mathrm{~mm}$ (long column) to analyze the influence of CFRP on the bearing capacity of members under failure modes of different lengths. For analyzing the effect of the fiber orientation on the load-carrying capacity of the components, the variable fiber orientation is set to $90^{\circ}$ (transverse, T) and $0^{\circ}$ (longitudinal, L); the fiber direction diagram is shown in Figure 8 [8]. A double layer of CFRP $(1 \mathrm{~T} 1 \mathrm{~L}, 2 \mathrm{~T}$, and $2 \mathrm{~L})$ is introduced to analyze the influence of the number of CFRP reinforcement layers on the bearing capacity of the members. To analyze the influence of different reinforcement locations of CFRP on the bearing capacity of long and short members, the reinforcement locations are classified as web + flanges + lips (WFL), web + flanges (WF), web only (W), and flanges only (F). The component number is shown in Table 4 . 


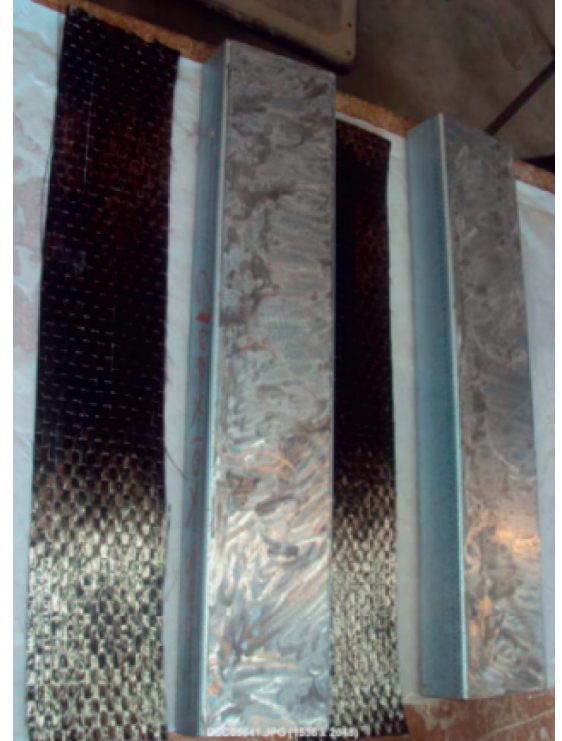

(a)

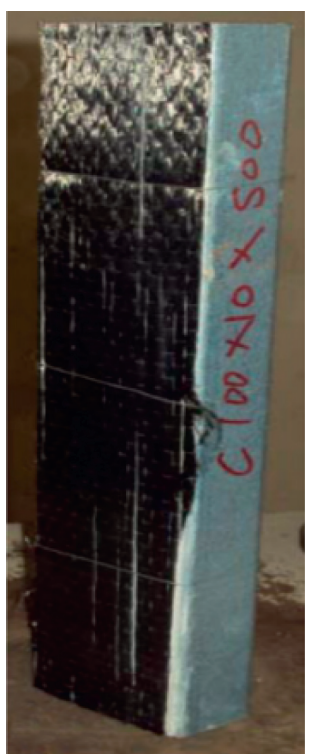

(b)

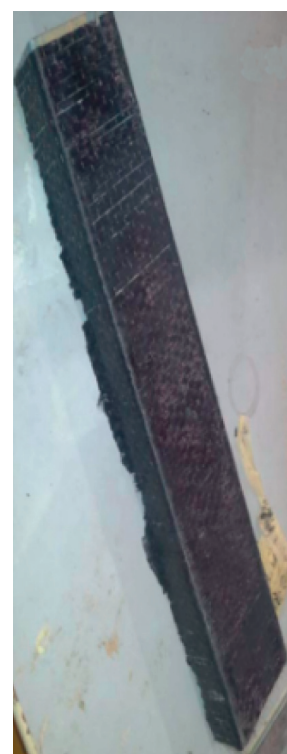

(c)

FIGURE 6: Cold-formed thin-walled steel strengthened by CFRP [19]: (a) plain section; (b) CFRP-strengthened web; (c) CFRP-strengthened full section.

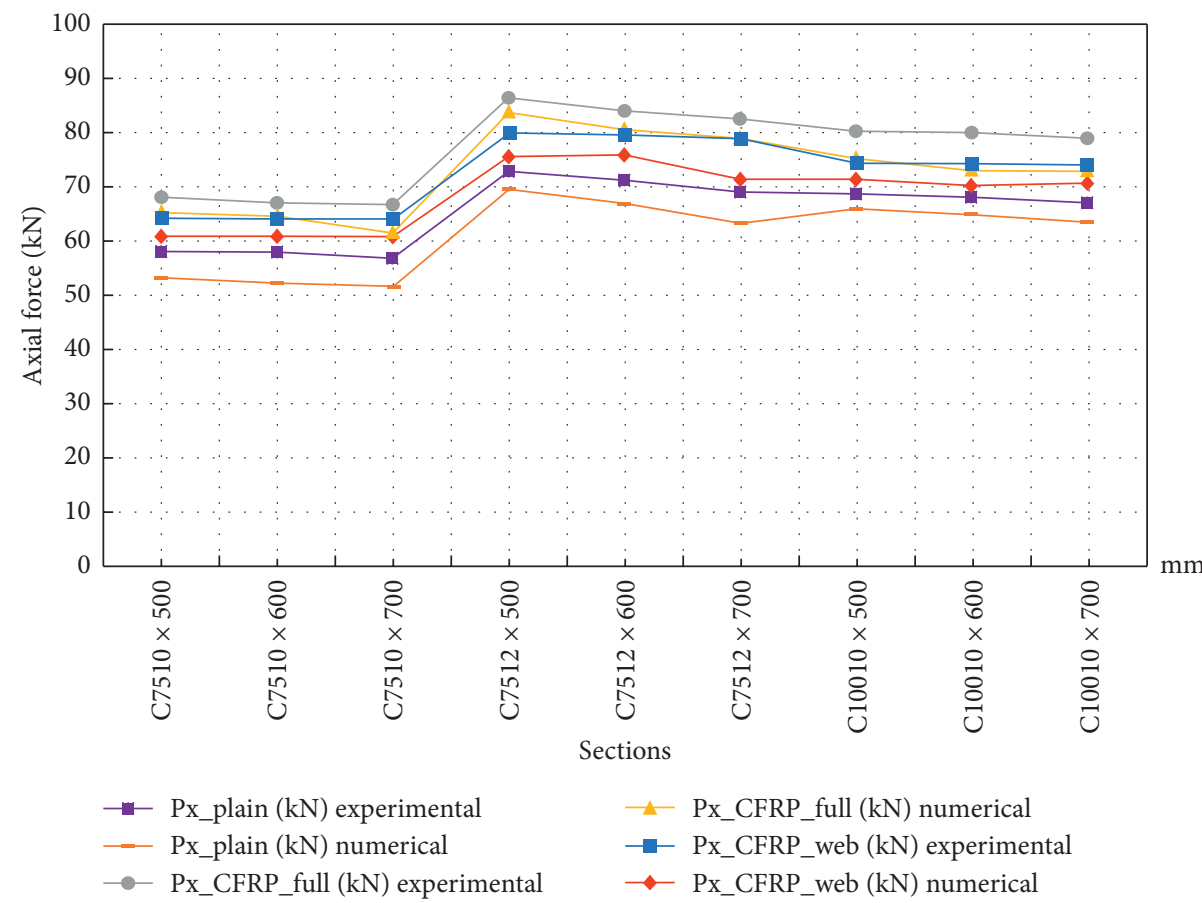

FIGURE 7: Numerical and experimental ultimate load of plain section, CFRP-strengthened web, and CFRP-strengthened full section.

The rule proposed by the works of Hashin and Rotem is adopted to simplify the method for introducing initial defects [30]. For long columns, 1.98t is used as the defect coefficient, and $1.55 t$ is used for short columns.

\subsection{Influence of CFRP Reinforcement Location and Fiber Orientation on Ultimate Load-Bearing Capacity.}

Figures 9(a)-9(d) give equilibrium paths, illustrating the variation in the column axial shortening with the applied load for the CFRP-strengthened single-layer short and long column components. Moreover, the simulated ultimate strength values are discussed in the next section. Figure 10 shows the numerical failure modes and the results are presented in these figures and tables prompt several observations. 


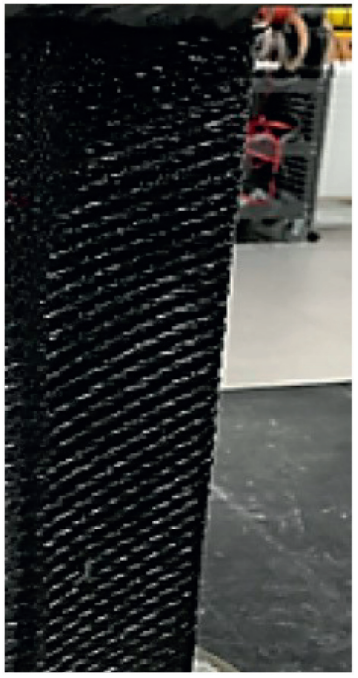

(a)

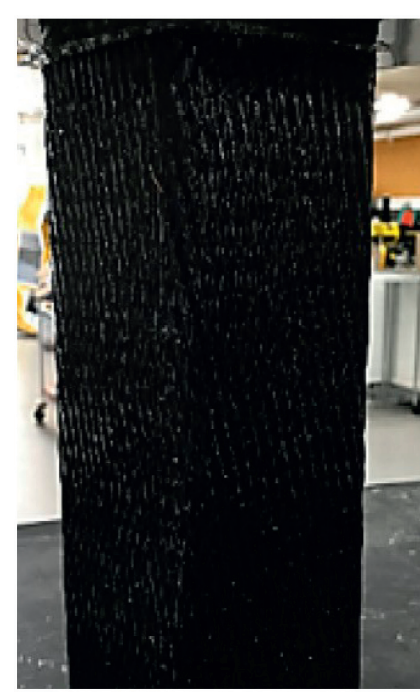

(b)

FIgURE 8: Fiber orientation diagram [8]. (a) Fiber orientation-transverse. (b) Fiber orientation-longitudinal.

TABle 4: Component number.

\begin{tabular}{|c|c|}
\hline Short column series & Long column series \\
\hline One ply & One ply \\
\hline S-N: short-column-without CFRP & L-N: long-column-without CFRP \\
\hline $\begin{array}{l}\text { S-F-L: short-column-flanges- } 0^{\circ} \text { (the flange of a short column with a fiber orientation } \\
\text { of } 0^{\circ} \text { ) }\end{array}$ & L-F-L: long-column-flanges- $0^{\circ}$ \\
\hline S-F-T: short-column-flanges- $90^{\circ}$ & L-F-T: long-column-flanges- $90^{\circ}$ \\
\hline S & L-W-L: long-colun \\
\hline S-W-T: short-column & L-W-T: long-column-web- $90^{\circ}$ \\
\hline+ flanges $-90^{\circ}$ & L-WF-T: long-column-web + flanges- $90^{\circ}$ \\
\hline & L-WF-L: long-colum \\
\hline S- & L-WFL-L: long-column- \\
\hline S-WFL-T: $s$ & L-WFL-T: long-column-web + flange \\
\hline Two plies & Two plies \\
\hline$/ 0^{\circ}$ (one fiber orientation of $90^{\circ}$, another & L-F-1T1L: long-column-flanges- $90^{\circ} / 0^{\circ}$ \\
\hline $2 \mathrm{P}$ is $\left.90^{\circ}\right)$ & L-F-2T: long-colum \\
\hline S-F-2L: sho & L-F-2L: long-column-flan \\
\hline S-W-1T1L: & L-W-1T1L: long-column-web- $90^{\circ} / 0^{\circ}$ \\
\hline S-W-2T: sl & L-W-2T: long-column-web- $90^{\circ}$ \\
\hline S-I & L-W-2L: long-column-web- $0^{\circ}$ \\
\hline S-I & L-WF-1T1L: long-column-web + flanges- $90^{\circ} / 0^{\circ}$ \\
\hline S-WF-2 & L-WF-2T: long-column-web + flanges- $90^{\circ}$ \\
\hline S-WF-2L: short-column-web + flanges- $0^{\circ}$ & L-WF-2L: long-colur \\
\hline S-WFL-1T1L: short-column-web + flanges + lips $-90^{\circ} / 0^{\circ}$ & $\begin{array}{l}\text { L-WFL-1T1L: long-column-web + flanges + lips- } \\
90^{\circ} / 0^{\circ}\end{array}$ \\
\hline S-WFL-2T: & L-WFL-2T: long-column-web + flanges + lips $-90^{\circ}$ \\
\hline S-WFL-2L: short-column-web + flanges + lips- 0 & L-WFL-2L: long-column-web + flanges + lips $-0^{\circ}$ \\
\hline
\end{tabular}

The failure modes of all columns are caused by the interaction of local torsional buckling modes, as shown in Figures $10(\mathrm{a})$ and $10(\mathrm{~b})$. It can provide the basis for the mechanism of buckling with torsion. From Figure 9, the members are basically in the elastic stage at the initial stage of loading. The members begin to enter the yield stage with increasing load. In the yield stage, the load and displacement behavior change from linear to nonlinear:
(1) For a short column member with a fiber orientation of $0^{\circ}$, Figure 9 (a) shows that the ultimate bearing capacity of the members strengthened is increased slightly compared with that of S-N at three different locations (S-W-L, S-WF-L, and S-F-L). The percentage increases are $3 \%, 5 \%$, and $4 \%$, respectively. Further strengthening at the lips (S-WFL-L) renders this increase slightly larger by $7 \%$. The comparatively 


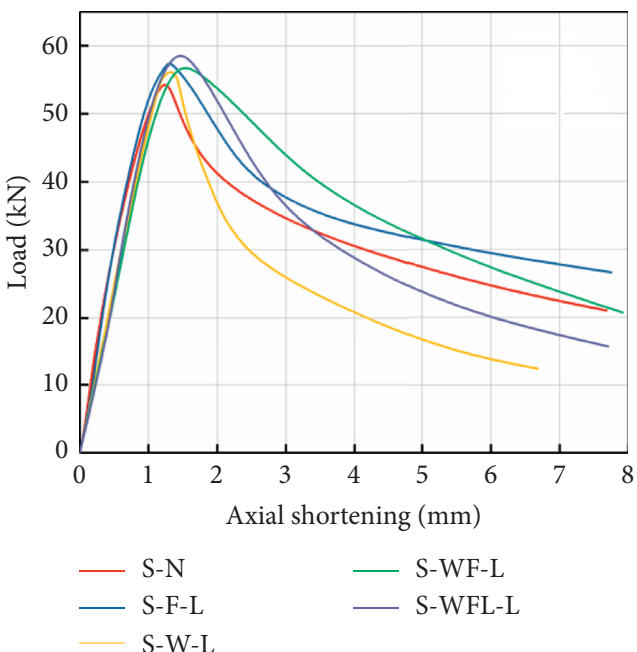

(a)

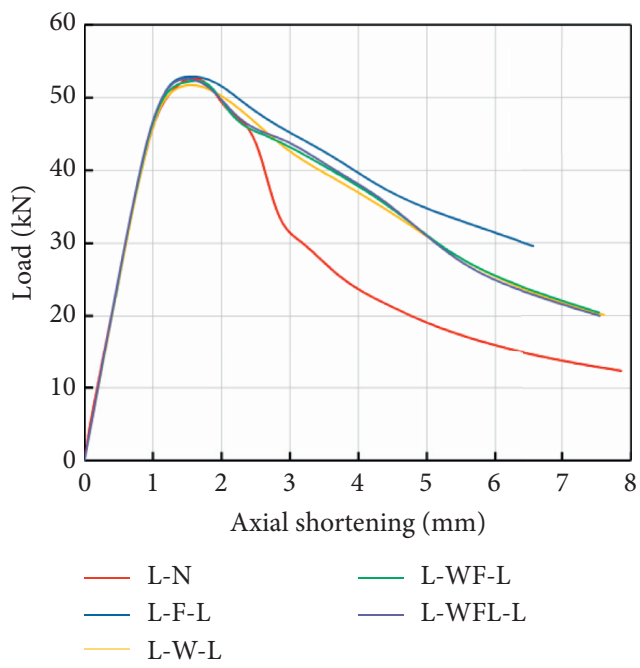

(c)

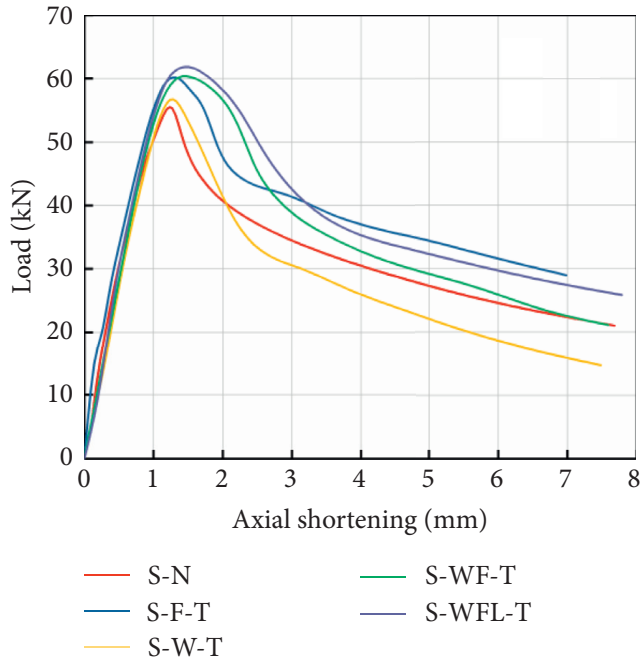

(b)

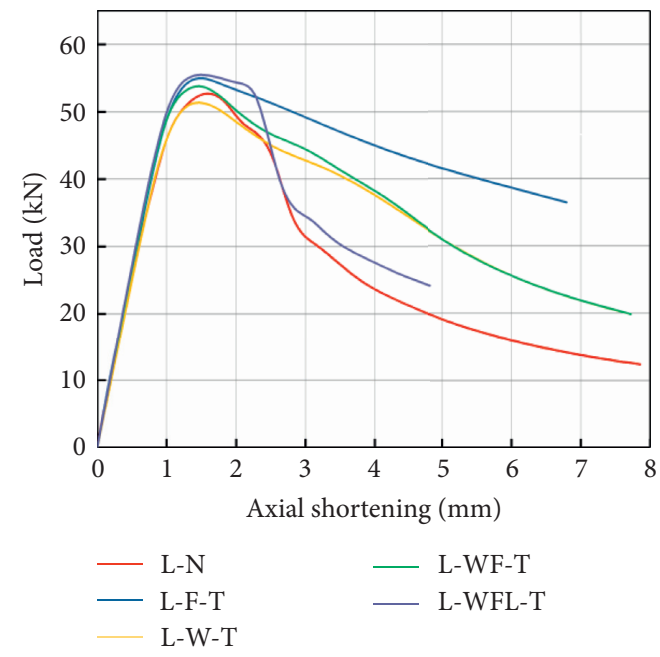

(d)

Figure 9: Curves for the (a) short column-fiber orientation $0^{\circ}$, (b) short column-fiber orientation $90^{\circ}$. (c) long column-fiber orientation $0^{\circ}$, and (d) long column-fiber orientation $90^{\circ}$.

effective of CFRP strengthening is associated with gluing the CFRP longitudinally to the web, flanges, and lips (S-WFL-L).

(2) From Figure 9, the ultimate load-bearing capacity of the member is not significantly increased compared with that of the bare column when the web position of the short column is strengthened by transverse fiber. The reason is that the size of the flanges of the member is longer and is thus prone to large deformations. After strengthening the web, deformation at the flanges can occur more easily, which leads to a nonobvious increase in the bearing capacity. Nonetheless, three types of reinforcement methods (S-WF-T, S-F-T, and S-WFL-T) provide clear improvement in the ultimate bearing capacity, leading to ultimate load increases of $8.1 \%, 7.2 \%$, and $10.2 \%$, respectively.
Accordingly, considering the range of increase in the ultimate load of the members, S-WF-T is a more efficient reinforcement technique for a CFRP layer on short columns. Nonetheless, S-WFL-T is the desperately advantageous reinforcement method if the bearing capacity of members needs to be maximally increased. From Figures 9(a) and 9(b), the reinforcement effect is better for short columns when the components are reinforced with transversely oriented fibers. Besides, the CFRP reinforcement delays the brittle phenomenon of a sudden decrease in the axial stiffness of the members. It can also be seen that, for short columns, the reinforcement effect is better when the components are reinforced with transversely oriented fibers. The CFRP reinforcement delays the brittle phenomenon of a sudden decrease in the axial stiffness of the members. 


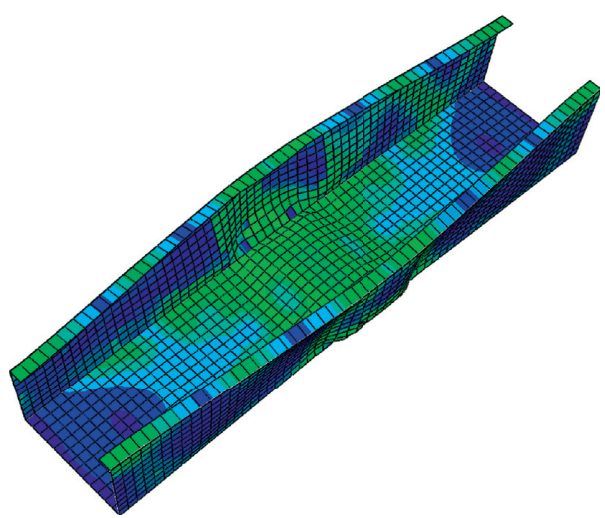

(a)

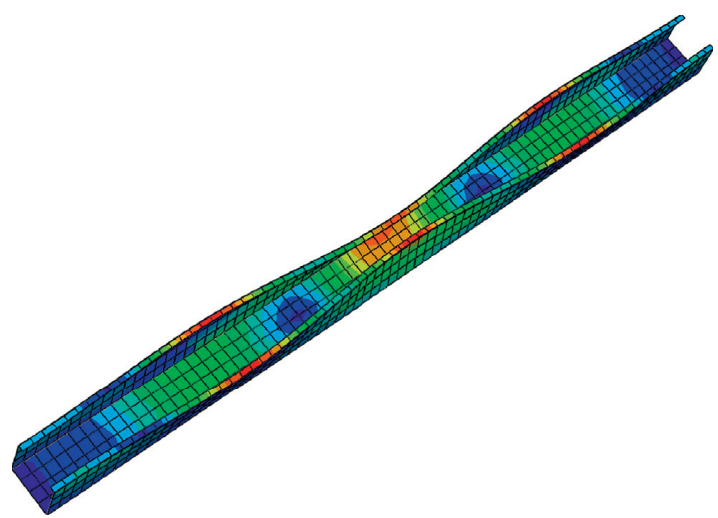

(b)

Figure 10: Numerical failure modes of the (a) S-F-0 and (b) L-F-0 columns.

(3) For the long column, the increase in the ultimate load is rather small compared with that of the bare column: $0.6 \%$ (L-F-L), $2 \%$ (L-WF-L), and 1.5\% (LWFL-L) when the flanges, both the web and the flanges, or the whole column are strengthened with longitudinal fibers. Figure 9(c) shows that the bearing capacity of the members strengthened through the web bonded with CFRP is similar to that of short column S-W-T. Hence, it is not recommended to enhance long columns with longitudinal fibers.

(4) Figure 9(d) gives that the ultimate load increases by $3.6 \%$ when the long column is strengthened with transversely oriented fibers, and both the web and the flanges are strengthened. Reinforcing only the flanges or the whole member results in improvements in the ultimate load of $5.3 \%$ and $7 \%$, respectively.

It can be seen that the L-WFL-T has significant enhancement effect for long columns considering the amount of increase in the ultimate bearing capacity. Yet the reinforcement effect for long columns strengthened with one layer of CFRP is not equal to that for short columns. As a consequence, multistory reinforcement can be considered to enhance the ultimate bearing capacity of the members when an actual project requires long members. In summary, the cold-formed thin-walled steel reinforced with a layer of CFRP can provide a better reinforcing effect, especially for short columns. A detailed description of the image fluctuation trend is presented in Table 5.

\subsection{Influence of CFRP Reinforcement Layer Number on Ul-} timate Bearing Capacity. Two layers of CFRP are considered to investigate the effect of the number of CFRP reinforcement layers on the ultimate load-bearing capacity. The fiber orientation of the two layers of CFRP is divided into three modes $(2 \mathrm{~T}, 2 \mathrm{~L}$, and $1 \mathrm{~T} 1 \mathrm{~L})$. In the $2 \mathrm{~T}$ mode, the fiber orientation of the first and second layers of CFRP is $90^{\circ}$. In this study, the ultimate load of the three different fiber orientations column is compared with a single-ply column and a
TABle 5: Component growth percentage.

\begin{tabular}{lc}
\hline Column & Gain (\%) \\
\hline Short column & \\
S-N & - \\
S-W-L & 3 \\
S-F-L & 4 \\
S-WF-L & 5 \\
S-WFL-L & 7 \\
S-F-T & 7.2 \\
S-WF-T & 8.1 \\
\hline Long column & \\
L-N & - \\
L-F-L & 2 \\
L-WF-L & 0.6 \\
L-WFL-L & 1.5 \\
L-F-T & 5.3 \\
L-WF-T & 3.6 \\
L-WFL-T & 7 \\
\hline
\end{tabular}

bare column. By comparing the data in Section 3.3, the influence of the orientation and position variables of the two-layer CFRP columns on the bearing capacity is roughly consistent with the law of single-layer CFRP columns. According to the analysis, the transverse fiber reinforcement method has a more significant impact on the bearing capacity performance if ignoring long columns and short columns. Hence, only the components that have a considerable effect on the bearing capacity are drawn in Figure 11. Tables 6 and 7 show a detailed description of the image fluctuation trend.

From Figure 11(a) and Tables 6 and 7, it is interesting to note that, compared to the bare column, the gain for the $\mathrm{S}-\mathrm{W}-1 \mathrm{~T} 1 \mathrm{~L}$ columns with two layers of CFRP is minimal. It demonstrates that strengthening only the web cannot provide sound reinforcement. It is not recommended to use it in practical projects. The other reinforcement methods, S-F1T1L, S-WF-1T1L, S-WFL-1T1L, S-F-2L, S-WF-2L, and S-WFL-2L, show improvements of $10.2 \%, 10.7 \%, 17.4 \%$, $6.4 \%, 7 \%$, and $17 \%$, respectively, over the bare column. S-F2L, S-WF-2L, and S-WFL-2L increase by $2.5 \%, 2.58 \%$, and $11.3 \%$, compared to S-F-L, S-WF-L, and S-WFL-L, respectively. S-F-1T1L, S-WF-1T1L, and S-WFL-1T1L lead to 


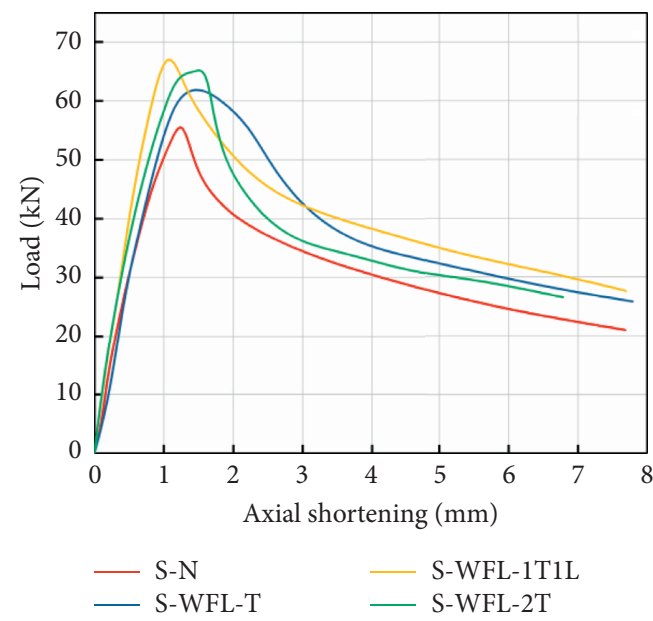

(a)

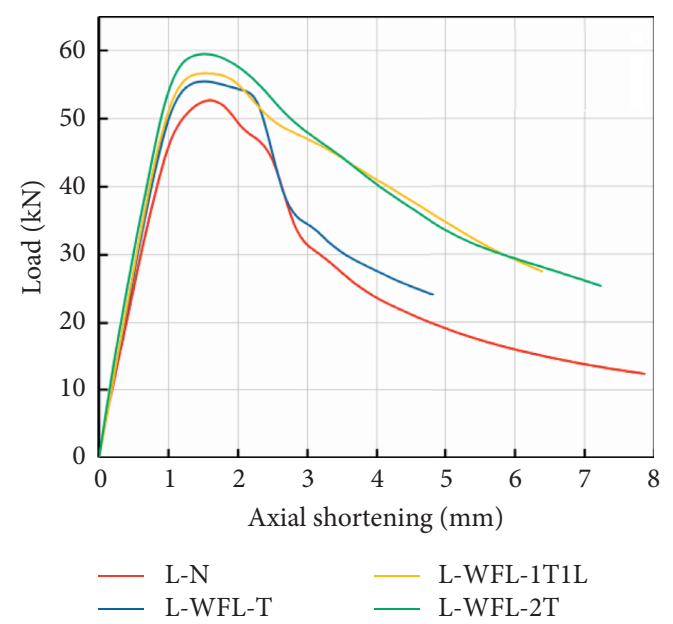

(b)

Figure 11: Curves for the (a) short columns,1T1L/2T/T/N, and (b) long columns, 1T1L/2T/T/N.

TABLE 6: Component growth percentage.

\begin{tabular}{lc}
\hline Column & Gain $(\%)$ \\
\hline Short column & \\
S-N & - \\
S-W-1T1L & 2.5 \\
S-W-2L & 4.4 \\
S-F-1T1L & 10.2 \\
S-WF-1T1L & 10.7 \\
S-WFL-1T1L & 17.4 \\
S-F-2L & 6.4 \\
S-WF-2L & 7 \\
S-WFL-2L & 17 \\
S-F-2T & 12.8 \\
S-W-2T & 3.1 \\
S-WF-2T & 13.2 \\
\hline Long column & \\
L-N & - \\
L-F-1T1L & 5.5 \\
L-WF-1T1L & 2.2 \\
L-WFL-1T1L & 8.5 \\
L-F-2L & 2 \\
L-WFL-2L & 4 \\
L-F-2T & 8.3 \\
L-WF-2T & 7.2 \\
L-WFL-2T & 12.8 \\
\hline
\end{tabular}

ultimate load increases of $4.1 \%, 4 \%$, and $0.43 \%$ compared to S-F-2L, S-WF-2L, and S-WFL-2L, respectively.

The above comparison of the bearing capacities indicates that the web + flange + lips (WFL) reinforcement of two layers of CFRP (1T1L) can provide the most significant improvement in the bearing load, while S-WFL-2L reinforcement can also play a similar role; the percentage increase is similar to that of $1 \mathrm{~T} 1 \mathrm{~L}$ reinforcement.

Furthermore, the results can reveal that, for the short column, placing the fibers at $90^{\circ}$ and gluing both layers of CFRP to the web provide almost no improvement in the bearing capacity compared to the bare column, while reinforcement as S-F-2T, S-WF-2T, and S-WFL-2T provides increases of $12.8 \%, 13.2 \%$, and $15 \%$, respectively, compared to S-N for the short column. Compared to S-F-T, S-WF-T, and S-WFL-T reinforcements, S-F-2T, S-WF-2T, and S-WFL-2T provide increases of $6 \%, 5.5 \%$, and $5 \%$, respectively. The ultimate bearing capacity with S-WFL-1T1L is $2.9 \%$ higher than that of S-WFL-2T. As a result, for the short column, the most useful CFRP strengthening is obtained by gluing two layers (1T1L) to the whole column.

The values presented in Figure 11(b) and Tables 6 and 7 for a fiber orientation of $0^{\circ}$ show that, compared to L-N, the L-F-1T1L, L-WF-1T1L, L-WFL-1T1L, L-F-2L, and L-WFL$2 \mathrm{~L}$, reinforcements exhibited increases of $5.5 \%, 2.2 \%, 8.5 \%$, $2 \%$, and $4 \%$, respectively. Additional strengthening of the lips (L-WFL-1T1L) renders this increase slightly larger: $8.5 \%$. It is preferable to orient one fiber layer at $0^{\circ}$ and the other at $90^{\circ}$ to increase the ultimate load, which leads to gains of up to $7 \%$ compared to L-WFL-L. Gluing one CFRP layer longitudinally and the other transversely to the flanges, both the web and flanges, or around the whole column, provide increases in the ultimate load of $3.6 \%, 3 \%$, and $4.7 \%$ compared to L-F-2L, L-WF-2L, and L-WFL-2L, respectively. Therefore, there is no apparent difference between the effect of bonding one layer or two layers of CFRP on the web or the web and flange when the orientation of the fiber is $0^{\circ}$. Generally, L-WFL-1T1L provides the best reinforcement effect.

Figure 11(b) and Tables 6 and 7 show that when the flanges or both web and flanges are strengthened with two CFRP layers oriented transversely, the ultimate load increases by $8.3 \%$ and $7.2 \%$, respectively, compared to the bare column. Additional strengthening of the lips (L-WFL-2T) renders this increase slightly more substantial by $12.8 \%$. Interestingly, the ultimate bearing capacity with L-WF-1T1L is lower than with L-WF-T. Compared to L-F-T, L-WF-T, and L-WFL-T, reinforcement with L-F-2T, L-WF-2T, and L-WFL-2T exhibited increases of $3.1 \%, 3.7 \%$, and $6.7 \%$, respectively. Compared to L-F-1T1L, L-WF-1T1L, and L-WFL-1T1L, the improvements with L-F-2T, L-WF-2T, and L-WFL-2T are $2.9 \%, 5.1 \%$, and $4.8 \%$, respectively. As a result, observation of (3) and (4) makes it possible to 
TABLE 7: Component growth percentage.

\begin{tabular}{|c|c|}
\hline Column & Gain (\%) \\
\hline \multicolumn{2}{|l|}{ Short column } \\
\hline S-F-2L/S-F-L & 2.5 \\
\hline S-W-2L/S-W-L & 1.3 \\
\hline S-WF-2L/S-WF-L & 2.58 \\
\hline S-WFL-2L/S-WFL-L & 11.3 \\
\hline S-F-1T1L/S-F-T & 3.2 \\
\hline S-WF-1T1L/S-WF-T & 2.8 \\
\hline S-WFL-1T1L/S-WFL-T & 7.7 \\
\hline S-F-2T/S-F-T & 6 \\
\hline S-W-2T/S-W-T & 0.53 \\
\hline S-WF-2 T/S-WF-T & 5.5 \\
\hline S-WFL-2T/S-WFL-T & 5 \\
\hline S-W-2L/S-W-1T1L & 1.8 \\
\hline S-F-1T1L/S-F-2L & 4.1 \\
\hline S-WF-1T1L/S-WF-2L & 4 \\
\hline S-WFL-1T1L/S-WFL-2L & 0.43 \\
\hline S-W-2T/S-W-1T1L & 0.6 \\
\hline S-F-2T/S-F-1T1L & 2.9 \\
\hline S-WF-2T/S-WF-1T1L & 2.8 \\
\hline S-WFL-1T1L/S-WFL-2T & 2.9 \\
\hline S-F-1T1L/S-F-L & 6.6 \\
\hline S-WF-1T1L/S-WF-L & 6.5 \\
\hline \multicolumn{2}{|l|}{ Long column } \\
\hline L-F-1T1L/L-F-L & 3.5 \\
\hline L-WF-1T1L/L-WF-L & 1.6 \\
\hline L-WFL-1T1L/L-WFL-L & 7 \\
\hline L-WFL-2L/L-WFL-L & 2.5 \\
\hline L-F-1T1L/L-F-T & 0.17 \\
\hline L-WF-T/L-WF-1T1L & 1.4 \\
\hline L-WFL-1T1L/L-WFL-T & 2 \\
\hline L-F-2T/L-F-T & 3.1 \\
\hline L-WF-2 T/L-WF-T & 3.7 \\
\hline L-WFL-2T/L-WFL-T & 6.7 \\
\hline L-F-1T1L/L-F-2L & 3.6 \\
\hline L-WF-1T1L/L-WF-2L & 3 \\
\hline L-WFL-1T1L/L-WFL-2L & 4.7 \\
\hline L-F-2T/L-F-1T1L & 2.9 \\
\hline L-WF-2T/L-WF-1T1L & 5.1 \\
\hline L-WFL-2T/L-WFL-1T1L & 4.8 \\
\hline
\end{tabular}

conclude that attaching two CFRP layers to the whole column provides the most significant reinforcement for long columns.

After the above analysis, it can be concluded that the range of increase in the reinforcement capacity for long columns is not as obvious as that for short columns. Hence, in practical engineering, to increase the ultimate load significantly, multi-ply reinforcement should be adopted for long columns. In conclusion, the fiber orientation, fiber reinforcement location, and the number of reinforcement layers all have a significant effect on the ultimate bearing capacity of members.

\section{Evaluation of Ultimate Bearing Capacity}

From the discussion in the last section, different reinforcement positions, orientations, and the number of layers of CFRP influence the ultimate bearing capacity of members. Hence, the orientation of the CFRP and the number of layers of CFRP should be considered in the calculation of the bearing capacity of members. The prediction equation given in [19] is modified based on the AISI-DSM. Also, an appropriately modified modulus design equation is proposed to predict the bearing capacity of CFRP-strengthened coldformed steel lipped channel columns.

4.1. Previous Studies. The assumptions adopted in the design of the bearing capacity of axially compressed cold-formed thin-walled steel members strengthened by CFRP in [19] are as follows:

(1) There is an adequate bond between the steel and CFRP.

(2) Slenderness of the composite plate is considered.

(3) CFRP yield stress is ignored for the composite section.

(4) The composite area is considered:

$$
\begin{gathered}
t_{t}=\left(t_{c f}\right)+t_{s}, \\
E_{\text {cfrp }}=\frac{E_{S} t_{s}+E_{c f} t_{c f}}{t_{s}+t_{c f}},
\end{gathered}
$$

where $t_{t}$ is thickness of composite section; $t_{c f}$ is CFRP thickness; $t_{s}$ is steel plate thickness; $E_{s}$ is elastic modulus of steel; $E_{c f}$ is elastic modulus of CFRP; and $E_{\text {cfrp }}$ is elastic modulus of the CFRP with steel.

From the work of Sreedhar Kalavagunta, the cross section thickness of the composite material is composed of the thickness of the CFRP and steel plate. The thickness of the adhesive layer is not considered, as in (8). The modulus of elasticity is calculated by considering the ratio of the modulus of CFRP to that of cold-formed thin-walled steel, as in (9). They apply the modified modulus of elasticity and properties of composite materials to the AISI-DSM to predict the bearing capacity of cold-formed thin-walled steel strengthened by CFRP.

Through the above analysis, it can be concluded that the number of CFRP-strengthened layers and the orientation of CFRP will have a significant impact on the modulus, which further affects the bearing capacity of CFRP-strengthened members. Yet the influence of the number and direction of CFRP reinforcement layers is not taken into account in (8) and (9). Therefore, they have been revised to obtain a new modified modulus calculation formula.

4.2. Modified Design Provisions. The FE simulation results show that the fiber orientation (vertical, transverse) and the number of reinforcement layers affect the increase in bearing capacity of reinforced members. Thus, it is necessary to introduce these factors into the equation for the bearing capacity. A proportional factor, $\xi$, is introduced to consider the effect of the fiber orientation on the bearing capacity. $N_{T}$ (number of transverse layers) and $N_{L}$ (number of 
longitudinal layers) are introduced to reflect the effect of the number of reinforcement layers on the bearing capacity:

$$
\begin{aligned}
t_{T} & =t+t_{c}\left(N_{L}+N_{T}\right), \\
E_{C E} & =\frac{N_{L} E_{1 C}+\xi N_{T} E_{1 C}}{N_{L}+N_{T}}, \\
E_{1 C} & =E_{C} \nu+E_{a}(1-\nu), \\
E & =\frac{E_{s} t_{s}+E_{C E} t_{c f}}{t_{s}+t_{c f}} .
\end{aligned}
$$

Assuming that the thickness of all transverse and longitudinal CFRP layers is equal, the equivalent stiffness method is used to calculate the CFRP modulus of elasticity. A proportional coefficient is introduced to calculate the CFRP modulus of elasticity. The proportional factor $(\xi)$ is used to transform the effect of transverse layers into the equivalent for longitudinal layers. The value of $\xi$ depends on the type of CFRP used. In this study, we tried to adopt the proportional factor proposed by experiments of Bambach [7]. Still, this proportional factor does not apply to 1T and 1L CFRP configurations. At present, there have been few studies on this topic. The selection of appropriate scale factors for different types of CFRP urgently needs to be investigated. So $\xi$ depends on the mechanical properties of the CFRP composite. The value is assigned 0.8 according to the detailed FE analysis results of this study [8]. The orientation of the CFRP fibers varies with the number of reinforcement layers when using multilayer CFRP to reinforce cold-formed thin-walled steel. Meanwhile, the equivalent elastic modulus $\left(E_{C E}\right)$ derived from (11) is adopted, in which $E_{1 c}$ represents the modulus of elasticity of CFRP in the tensile direction, which can be measured through tensile tests of the material or calculated using (12). In (12), $v$ denotes the volume ratio of fibers, $E_{\mathrm{C}}$ and $E_{\mathrm{a}}$ represent the elastic modulus of the CFRP and the adhesive layer, respectively, and $t_{T}$ is the total thickness of the composite section in terms of the CFRP composite layer thickness $\left(t_{c}\right)$.

4.3. Direct Strength Method (DSM) Equations. The DSM uses member elastic buckling solutions based on gross crosssectional properties instead of the effective width to determine the member strength. The DSM is an alternative design method, allowing computation of the compression capacities of sections, provided the elastic buckling load $\left(P_{\mathrm{cr}}\right)$ and yield load $\left(P_{y}\right)$ of the section are known. The DSM is included in AS/NZS 4600 as well as Appendix 1 of the AISI S100 Standard [36-38].

\subsubsection{Design Rules for Axial Compression}

(1) Flexural, torsional, or torsional-flexural buckling $\left(P_{\text {ne }}\right)$

The nominal axial strength (resistance), $P_{\text {ne, for }}$ flexural, torsional, or flexural-torsional buckling should be calculated as follows: (a) For $\lambda_{c} \leq 1.5$,

$$
\begin{aligned}
& P_{\text {ne }}=\left(0.658^{\lambda_{c}^{2}}\right) P_{y} . \\
& P_{n e}=\left(\frac{0.877}{\lambda_{c}^{2}}\right) P_{y}, \\
& P_{n l}=P_{n e} . \\
& P_{n l}=\left[1-0.15\left(\frac{P_{c r l}}{P_{n e}}\right)^{0.4}\right]\left(\frac{P_{c r l}}{P_{n e}}\right)^{0.4} P_{n e}, \\
& P_{n d}=P_{y} . \\
& P_{n d}=\left(1-0.25\left(\frac{P_{c r d}}{P_{y}}\right)^{0.6}\right)\left[\frac{P_{c r d}}{P_{y}}\right]^{0.6} P_{y},
\end{aligned}
$$

where $\lambda_{d}=\sqrt{P_{y} / P_{c r d}}$, in which $P_{c r d}$ is the critical elastic distortional column buckling load.

(b) For $\lambda_{\mathrm{c}}>1.5$,

where $\lambda_{c}=\sqrt{P_{y} / P_{\text {cre }}}$, in which $P_{y}=A_{g} f_{y}$ and $A_{s}$ and $A_{c}$ are the gross section areas of steel and the CFRP, respectively; $A_{g}=A_{s}+A_{c}\left(E_{1 c} / E_{s}\right)$ is the gross section area, where $E_{s}$ denotes the elastic modulus of the steel bars. $P_{\text {cre }}$ is the minimum critical elastic column buckling load in flexural, torsional, or flexural-torsional buckling [39-41].

(2) Local buckling $\left(P_{n l}\right)$

The nominal axial strength (resistance), $P_{n l}$, for local buckling should be calculated as follows:

(a) For $\lambda_{l} \leq 0.776$,

(b) For $\lambda_{l}>0.776$,

where $\lambda_{l}=\sqrt{P_{n e} / P_{c r l}}$, in which $P_{c r l}$ is the critical elastic local column buckling load.

(3) Distorted buckling $\left(P_{n d}\right)$

The nominal axial strength (resistance), $P_{n d}$, for distorted buckling should be calculated as follows:

(a) For $\lambda_{d} \leq 0.561$,

(b) For $\lambda_{d}>0.561$,

The column ultimate load is as follows:

$$
P_{u}=\min \left\{P_{n E} ; P_{n L} ; P_{n D}\right\} \text {. }
$$

4.4. Assessment of the Modified AISI Ultimate Load Estimates. Tables 8-11, respectively, list the ultimate load values obtained using the above design method along with the ultimate load $P_{u}$, obtained by the numerical calculation. In addition, the tables also show the ratio of the estimated limit load $P_{u, a p}$ to the numerical simulation value $P_{u}$.

Finally, the safety and accuracy of the ultimate load are assessed by the proposed new formula. The short and long 
TABLE 8: Load estimates, for the short columns.

\begin{tabular}{lccc}
\hline Section & $\begin{array}{c}P_{u}(\mathrm{kN}) \\
\text { FEA }\end{array}$ & $\begin{array}{c}P_{u, a p}(\mathrm{kN}) \\
\text { AISI }\end{array}$ & $P_{u, a p} / P_{u}$ \\
\hline 1 ply & & & \\
S-N & 55.294 & 56.9 & 1.029 \\
S-F-L & 57.547 & 59.6 & 1.036 \\
S-W-L & 56.985 & 55.3 & 0.970 \\
S-WF-L & 57.915 & 59.4 & 1.026 \\
S-WFL-L & 59.147 & 60.5 & 1.023 \\
S-F-T & 59.634 & 61.2 & 1.026 \\
S-W-T & 56.73 & 58.3 & 1.028 \\
S-WF-T & 60.182 & 58.2 & 0.967 \\
S-WFL-T & 61.759 & 62.3 & 1.009 \\
\hline
\end{tabular}

TABLE 9: Load estimates, for the long columns.

\begin{tabular}{llll}
\hline Section & $\begin{array}{c}P_{u}(\mathrm{kN}) \\
\text { FEA }\end{array}$ & $\begin{array}{c}P_{u, a p}(\mathrm{kN}) \\
\text { AISI }\end{array}$ & $P_{u, a p} / P_{u}$ \\
\hline 1 ply & & & \\
L-N & 51.784 & 53.4 & 1.031 \\
L-F-L & 52.859 & 51.3 & 0.971 \\
L-W-L & 51.6 & 52.7 & 1.021 \\
L-WF-L & 52.106 & 55.8 & 1.071 \\
L-WFL-L & 52.583 & 50.2 & 0.955 \\
L-F-T & 54.703 & 56.3 & 1.029 \\
L-W-T & 51.326 & 52.5 & 1.023 \\
L-WF-T & 53.709 & 55.1 & 1.026 \\
L-WFL-T & 55.442 & 54.3 & 0.979 \\
\hline
\end{tabular}

TABLe 10: Short column ultimate load estimates, for 1, 2 CFRPS.

\begin{tabular}{lccc}
\hline Section & $\begin{array}{c}P_{u}(\mathrm{kN}) \\
\text { FEA }\end{array}$ & $\begin{array}{c}P_{u, a p}(\mathrm{kN}) \\
\text { AISI }\end{array}$ & $P_{u, a p} / P_{u}$ \\
\hline 1 ply & & & \\
S-N & 55.294 & 56.9 & 1.029 \\
S-F-L & 57.547 & 59.6 & 1.036 \\
S-W-L & 56.985 & 55.3 & 0.970 \\
S-WF-L & 57.915 & 59.4 & 1.026 \\
S-WFL-L & 59.147 & 60.5 & 1.023 \\
S-F-T & 59.634 & 61.2 & 1.026 \\
S-W-T & 56.73 & 58.3 & 1.028 \\
S-WF-T & 60.182 & 58.2 & 0.967 \\
S-WFL-T & 61.759 & 62.3 & 1.009 \\
\hline 2 plies & & & \\
S-F-1T1L & 61.598 & 63.8 & 1.036 \\
S-W-1T1L & 56.71 & 58.2 & 1.026 \\
S-WF-1T1L & 61.931 & 63.4 & 1.024 \\
S-WFL-1T1L & 66.933 & 64.2 & 0.959 \\
S-F-2T & 63.419 & 65.7 & 1.036 \\
S-W-2T & 57.035 & 58.4 & 1.024 \\
S-WF-2T & 63.709 & 64.3 & 1.009 \\
S-WFL-2T & 65.024 & 67.5 & 1.038 \\
S-F-2L & 59.048 & 58.5 & 0.991 \\
S-W-2L & 57.734 & 59.2 & 1.025 \\
S-WF-2L & 59.449 & 61.3 & 1.031 \\
S-WFL-2L & 66.648 & 68.4 & 1.026 \\
\hline
\end{tabular}

column ultimate loads obtained with the proposed new method are quite accurate (2\% and 5\% mean errors, respectively). Moreover, the values also exhibit a rather low
TABle 11: Long column ultimate load estimates, for 1, 2 CFRPS.

\begin{tabular}{lccc}
\hline Section & $\begin{array}{c}P_{u}(\mathrm{kN}) \\
\text { FEA }\end{array}$ & $\begin{array}{c}P_{u, a p}(\mathrm{kN}) \\
\text { AISI }\end{array}$ & $P_{u, a p} / P_{u}$ \\
\hline 1 ply & & & \\
L-N & 51.784 & 53.4 & 1.031 \\
L-F-L & 52.859 & 51.3 & 0.971 \\
L-W-L & 51.6 & 52.7 & 1.021 \\
L-WF-L & 52.106 & 55.8 & 1.071 \\
L-WFL-L & 52.583 & 50.2 & 0.955 \\
L-F-T & 54.703 & 56.3 & 1.029 \\
L-W-T & 51.326 & 52.5 & 1.023 \\
L-WF-T & 53.709 & 55.1 & 1.026 \\
L-WFL-T & 55.442 & 54.3 & 0.979 \\
\hline 2 plies & & & \\
L-F-1T1L & 54.8 & 56.2 & 1.026 \\
L-W-1T1L & 51.282 & 50.2 & 0.979 \\
L-WF-1T1L & 52.965 & 50.6 & 0.955 \\
L-WFL-1T1L & 56.57 & 58.9 & 1.041 \\
L-F-2T & 56.463 & 59.3 & 1.050 \\
L-W-2T & 51.163 & 50.3 & 0.983 \\
L-WF-2T & 55.817 & 57.4 & 1.028 \\
L-WFL-2T & 59.392 & 55.2 & 0.929 \\
L-F-2L & 52.826 & 54.6 & 1.034 \\
L-W-2L & 51.531 & 50.1 & 0.972 \\
L-WF-2L & 51.379 & 53.6 & 1.043 \\
L-WFL-2L & 53.928 & 55.1 & 1.022 \\
\hline
\end{tabular}

scatter. From the previous tables, it can be concluded that the results calculated with the revised formula are in good agreement with those obtained with the numerical simulation, which verifies the correctness of the revised formula.

\section{Conclusions}

(1) For a short column member with a fiber orientation of $0^{\circ}$, the comparatively effective of CFRP strengthening is associated with gluing the CFRP longitudinally to the web, flanges, and lips (S-WFL$\mathrm{L})$. The S-WFL-T is the best reinforcement method for a CFRP layer on short columns when the member is strengthened with transversely oriented fibers. Compared with the increase of the bearing capacity of the two short column reinforcement methods, $\mathrm{S}$-WFL-T is also the best reinforcement method for the short column. Besides, the reinforcement effect is better when the components are reinforced with transversely oriented fibers compared with longitudinally.

(2) There is no apparent difference between the effect of bonding one layer of CFRP on the web for the long column when the orientation of the fiber is $0^{\circ}$. The effect of CFRP-strengthening the whole column with gluing the one-layer CFRP transversely is more significant for long columns. The cold-formed thinwalled steel reinforced with a layer of CFRP can provide a better reinforcing effect, especially for short columns.

(3) Compared to the bare column, the gain for the S-W1T1L columns with two layers of CFRP is minimal, 
which demonstrates that strengthening only the web cannot provide sound reinforcement. It is not recommended to use this reinforcement method in practical projects for a short column. The relatively efficacious way to improve the ultimate bearing capacity of short columns is to apply a full section reinforcement with one layer of transverse CFRP and one layer of horizontal CFRP.

(4) There is no apparent difference between the effect of bonding two layers of CFRP on the web or the web and flange for the long column when the orientation of the fiber is $0^{\circ}$. A more useful approach to improve the ultimate bearing capacity of long columns is to use a full section reinforcement with two layers of transverse CFRP. Still, the reinforcement effect is not visible compared with those short columns. For this reason, multiplies strengthening can be considered to enhance the ultimate bearing capacity of members when the members are long in practical engineering.

(5) The short and long column ultimate loads obtained with the proposed new method are entirely accurate ( $2 \%$ and $5 \%$ mean errors, respectively). Moreover, the values also exhibit a rather low scatter. So, the modified formula can accurately estimate the ultimate bearing capacity of the cold-bending thinwalled C-section steel column reinforced by fiber.

\section{Data Availability}

The data used to support the findings of this study are available from the corresponding author upon request.

\section{Conflicts of Interest}

The authors declare that they have no conflicts of interest.

\section{Acknowledgments}

The authors express great appreciation to financial support from China Scholarship Council (Grant: CSC 201908510201).

\section{References}

[1] W. Yu, Cold-Formed Steel Design, John Wiley \& Sons, Hoboken, NJ, USA, 3rd edition, 2002.

[2] X.-L. Zhao and L. Zhang, "State-of-the-art review on FRP strengthened steel structures," Engineering Structures, vol. 29, no. 8, pp. 1808-1823, 2007.

[3] J. Haedir and X.-L. Zhao, "Design of short CFRP-reinforced steel tubular columns," Journal of Constructional Steel Research, vol. 67, no. 3, pp. 497-509, 2011.

[4] A. A. Ei Damatty, M. Abushagur, and M. A. Youssef, "Experimental and analytical investigation of steel beams rehabilitated using GFRP sheets," Steel and Composite Structures, vol. 3, no. 6, pp. 421-438, 2003.

[5] K. Narmashiri, N. H. Ramli Sulong, and M. Z. Jumaat, "Failure analysis and structural behaviour of CFRP strengthened steel I-beams," Construction and Building Materials, vol. 30, pp. 1-9, 2012.
[6] J. Yuan, C. Wang, X. Li, and Q. Xu, "Experimental research on $\mathrm{H}$-shaped steel beam strengthened with CFRP," Building Structure, vol. 41, pp. 116-119, 2011.

[7] M. R. Bambach, H. H. Jama, and M. Elchalakani, "Axial capacity and design of thin-walled steel SHS strengthened with CFRP," Thin-Walled Structures, vol. 47, no. 10, pp. 1112-1121, 2009.

[8] M. Imran, M. Mahendran, and P. Keerthan, "Experimental and numerical investigations of CFRP strengthened short SHS steel columns," Engineering Structures, vol. 175, pp. 879-894, 2018.

[9] D. Fernando, T. Yu, J. G. Teng, and X. L. Zhao, "CFRP strengthening of rectangular steel tubes subjected to end bearing loads: effect of adhesive properties and finite element modelling," Thin-Walled Structures, vol. 47, no. 10, pp. 1020-1028, 2009.

[10] A. H. Al-Saidy, F. W. Klaiber, and T. J. Wipf, "Repair of steel composite beams with carbon fiber-reinforced polymer plates," Journal of Composites for Construction, vol. 8, no. 2, pp. 163-172, 2004.

[11] P. Colombi and C. Poggi, "An experimental analytical and numerical study of the static behaviour of steel beams reinforced by pultruded CFRP strips," Composites Part B: Engineering, vol. 37, no. 1, pp. 64-73, 2006.

[12] J. Haedir and X.-L. Zhao, "Design of CFRP-strengthened steel CHS tubular beams," Journal of Constructional Steel Research, vol. 72, pp. 203-218, 2012.

[13] Y. Chen, R. Feng, and J. Xu, "Flexural behaviour of CFRP strengthened concrete-filled aluminium alloy CHS tubes," Construction and Building Materials, vol. 142, pp. 295-319, 2017.

[14] M. J. Chajes, T. A. Thomson Jr., T. F. Januszka, and W. W. Finch Jr., "Flexural strengthening of concrete beams using externally bonded composite materials," Construction and Building Materials, vol. 8, no. 3, pp. 191-201, 1994.

[15] J. G. Teng, T. Yu, and D. Fernando, "Strengthening of steel structures with fiber-reinforced polymer composites," Journal of Constructional Steel Research, vol. 78, pp. 131-143, 2012.

[16] A. Shaat and A. Fam, "Axial loading tests on short and long hollow structural steel columns retrofitted using carbon fibre reinforced polymers," Canadian Journal of Civil Engineering, vol. 33, no. 4, pp. 458-470, 2006.

[17] A. Shaat and A. Fam, "Fiber-element model for slender HSS columns retrofitted with bonded high-modulus composites," Journal of Structural Engineering, vol. 133, no. 1, pp. 85-95, 2007.

[18] M. C. Sundarraja, P. Sriram, and G. Ganesh Prabhu, "Strengthening of hollow square sections under compression using FRP composites," Advances in Materials Science and Engineering, vol. 2014, Article ID 396597, 19 pages, 2014.

[19] S. Kalavagunta, S. Naganathan, and K. N. Bin Mustapha, "Proposal for design rules of axially loaded CFRP strengthened cold formed lipped channel steel sections," Thin-Walled Structures, vol. 72, pp. 14-19, 2013.

[20] M. I. Alam, S. Fawzia, and X. Liu, "Effect of bond length on the behaviour of CFRP strengthened concrete-filled steel tubes under transverse impact," Composite Structures, vol. 132, pp. 898-914, 2015.

[21] S. Fawzia, X. L. Zhao, R. Al-Mahaidi, and S. Rizkalla, "Bond characteristics betweencfrp and steel plates in double strap joints," Advanced Steel Construction, vol. 1, pp. 17-27, 2005.

[22] J. G. Teng, D. Fernando, and T. Yu, "Finite element modelling of debonding failures in steel beams flexurally strengthened with CFRP laminates," Engineering Structures, vol. 86, pp. 213-224, 2015. 
[23] A. Al-Mosawe, R. Al-Mahaidi, and X.-L. Zhao, "Effect of CFRP properties, on the bond characteristics between steel and CFRP laminate under quasi-static loading," Construction and Building Materials, vol. 98, pp. 489-501, 2015.

[24] H. Al-Zubaidy, R. Al-Mahaidi, and X.-L. Zhao, "Finite element modelling of CFRP/steel double strap joints subjected to dynamic tensile loadings," Composite Structures, vol. 99, pp. $48-61,2013$.

[25] A. Faggiani and B. G. Falzon, "Predicting low-velocity impact damage on a stiffened composite panel," Composites Part A: Applied Science and Manufacturing, vol. 41, no. 6, pp. 737$749,2010$.

[26] F. Nunes, J. R. Correia, and N. Silvestre, "Structural behavior of hybrid FRP pultruded beams: experimental, numerical and analytical studies," Thin-Walled Structures, vol. 106, pp. 201217, 2016.

[27] M. H. Kabir, S. Fawzia, T. H. T. Chan, J. C. P. H. Gamage, and J. B. Bai, "Experimental and numerical investigation of the behaviour of CFRP strengthened CHS beams subjected to bending," Engineering Structures, vol. 113, pp. 160-173, 2016.

[28] P. Naghipour, J. Schneider, M. Bartsch, J. Hausmann, and H. Voggenreiter, "Fracture simulation of CFRP laminates in mixed mode bending," Engineering Fracture Mechanics, vol. 76, no. 18, pp. 2821-2833, 2009.

[29] M. L. Benzeggagh and M. Kenane, "Measurement of mixedmode delamination fracture toughness of unidirectional glass/ epoxy composites with mixed-mode bending apparatus," Composites Science and Technology, vol. 56, no. 4, pp. 439-449, 1996.

[30] Z. Hashin and A. Rotem, "A fatigue failure criterion for fiber reinforced materials," Journal of Composite Materials, vol. 7, no. 4, pp. 448-464, 1973.

[31] Z. Haszin, "Failure criteria for unidirectional fiber composites," Journal of Applied Mechanics, vol. 48, no. 4, pp. 846-852, 1981.

[32] D. Mostofinejad and N. Moshiri, "Compressive strength of CFRP composites used for strengthening of RC columns: comparative evaluation of EBR and grooving methods," Journal of Composites for Construction, vol. 19, pp. 1-11, 2015.

[33] M. Lesani, M. R. Bahaari, and M. M. Shokrieh, "Numerical investigation of FRP-strengthened tubular T-joints under axial compressive loads," Composite Structures, vol. 100, pp. 71-78, 2013.

[34] N. Silvestre, B. Young, and D. Camotim, "Non-linear behaviour and load-carrying capacity of CFRP-strengthened lipped channel steel columns," Engineering Structures, vol. 30, no. 10, pp. 2613-2630, 2008.

[35] National Standard of PRC, Technical Code of Cold-Formed Thin-Wall Steel structures: GB50018-2002, China Planning Press, Beijing, China, 2002.

[36] Standards Australia/Standards New Zealand, AS/NZS 4600 Cold-Formed Steel Structures, Standards Australia/Standards New Zealand, Sydney, Australia, 2005.

[37] G. Qin, P. Zhang, X. Hou, S. Wu, and Y. Wang, "Risk assessment for oil leakage under the common threat of multiple natural hazards," Environmental Science and Pollution Research, vol. 27, no. 14, pp. 16507-16520, 2020.

[38] American Iron Steel Institute (AISI), North American Specification for the Design of Cold-Formed Steel Structural Members, AISI, Washington, DC, USA, 2007.

[39] J. Xu, H. Wang, Y. Liu et al., "Ecological risk assessment of heavy metals in soils surrounding oil waste disposal areas," Environmental Monitoring and Assessment, vol. 188, no. 2, p. 125, 2016.
[40] G. Zhang, B.-J. He, and B. J. Dewancker, "The maintenance of prefabricated green roofs for preserving cooling performance: a field measurement in the subtropical city of Hangzhou, China," Sustainable Cities and Society, vol. 61, Article ID 102314, 2020.

[41] G. Qin, P. Zhang, and Y. Wang, "Investigating an assessment model of system oil leakage considering failure dependence," Environmental Science and Pollution Research, vol. 24, no. 30, pp. 1-13, 2020. 